\title{
DESLOCAMENTO, FORMAÇÃO E LEGITIMAÇÃO: uma análise de programas de residência artística no Brasil ${ }^{1}$
}

\author{
Guilherme Marcondes*
}

\begin{abstract}
No universo da arte contemporânea brasileira, instituições públicas ou privadas divulgam anualmente editais voltados para jovens artistas, cujo objetivo é fomentar o seu deslocamento para espaços diferenciados de interação social e trocas, a fim de incentivar sua produção. Nas residências, o artista complementa e aprimora sua formação através de novas experiências com o entorno, desenvolvendo seu trabalho longe do ambiente de costume. Neste artigo, objetiva-se compreender como tais programas têm alterado os processos de formação e legitimação de artistas no Brasil. Para isso, são analisados os editais de seleção de três programas de residência artística: o Programa Bolsa Pampulha, promovido, desde 2003, pela Prefeitura Municipal de Belo Horizonte, no Museu de Arte da Pampulha; a Casa B-Residência Artística, lançada em 2016 pelo Museu do Bispo Rosário Arte Contemporânea (MBRAC), no Rio de Janeiro, com incentivo da FUNARTE; e a Residência Artística Red Bull Station, iniciativa financiada pela empresa austríaca Red Bull em São Paulo, desde 2013
\end{abstract}

PALAVRAS-CHAVE: Arte contemporânea. Jovens artistas. Residências artísticas. Deslocamento. Legitimação. Carreira.

\section{INTRODUÇÃO}

Com o advento da arte contemporânea, a produção artística sofreu uma mudança profunda, cujos efeitos e consequências apenas recentemente começaram a ser avaliados de uma perspectiva sociológica. Questionando as antigas concepções de arte, o movimento e a instauração da arte contemporânea provocaram transformações radicais na concepção, reprodução, conservação, exibição, observação e comercialização de trabalhos de arte, como afirma a socióloga Natalie Heinich (2014), ressaltando que um novo paradigma artístico vem moldando o conjunto das atividades relacionado com as artes, o que inclui novos atores sociais, como curadores e mediadores, além

\footnotetext{
* Universidade Estadual do Ceará. Programa de Pós-Graduação em Sociologia.

Av. Dr. Silas Munguba, 1700, Campus do Itaperi. Cep: 60714-903. Fortaleza - Ceará - Brasil. gui.marcondesss@ gmail.com

(https://orcid.org/0000-0001-6114-7944)

${ }^{1}$ Este artigo traz um recorte de questões e resultados apresentados na tese de doutorado intitulada Arte e Consagração: Os Jovens Artistas da Arte Contemporânea, por mim defendida em maio de 2018, no Programa de Pós-Graduação em Sociologia e Antropologia da Universidade Federal do Rio de Janeiro (PPGSA/UFRJ).
}

de um conjunto diferenciado de especialistas, bancos e empresas de toda a sorte.

Uma das mudanças mais sensíveis diz respeito ao caráter objetual da arte, que perde sua primazia em detrimento de ações e proposições de caráter estético. A arte contemporânea aparece e desaparece em locais diferentes, em ruas, praças, florestas ou museus e centros culturais, estabelecendo uma nova temporalidade. De acordo com Villas Bôas,

[...] uma forte tendência contemporânea pretende ligar "arte e vida", como se ela tivesse que descer de seu pedestal, imiscuindo-se no mundo como um objeto entre tantos outros, não mais para ser contemplado ritual e religiosamente, mas para retirar o espectador de sua conformidade passiva, provocando-lhe reações das mais inesperadas, arrancando-o finalmente de sua zona de conforto (Villas Bôas, 2017, p. 99).

Na década de 1960, críticos de arte e artistas começaram a defender uma nova política para o espectador, incentivando sua efetiva participação nas expressões artísticas. ${ }^{2} \mathrm{~A}$

${ }^{2}$ Em $A$ vontade poética no diálogo com os bichos: o ponto de chegada de uma arte participativa no Brasil (2003), Felipe Scovino, ao tratar da contribuição de Lygia Clark para o desenvolvimento, no Brasil, da chamada arte participativa que, em linhas gerais, implica uma participação do públi$\mathrm{co}$, o autor adverte que se convencionou tratar do tema 
natureza política e transgressora da produção, que foi surgindo naquela época, teve grande repercussão (Erber, 2015, p 1-11), buscando retirar os artistas de seu isolamento e convocá-los a assumirem posições em um mundo cheio de conflitos. Como não podia deixar de ser, as mudanças brevemente apontadas acima provocaram o desmantelamento das antigas modalidades de formação, circulação e legitimação dos jovens artistas. ${ }^{3}$

O presente artigo problematiza a institucionalização e o crescimento das residências artísticas, indagando em que medida elas configuram uma nova modalidade de formação e legitimação dos artistas na arte contemporânea. As residências, cujo crescimento está definitivamente associado à arte contemporânea, definem-se como empreendimentos de instituições públicas ou privadas que proporcio-

sem, no entanto, abordar diferenças em relação ao que seja esse tipo de arte que convoca o público para a ação. Essa diferenciação é o objeto do artigo de Scovino.

${ }^{3}$ Aqui tomada como categoria analítica presente no campo da arte, a noção de jovem artista, tratada na tese de doutorado que baliza este artigo (Marcondes, 2018), diz respeito ao entrelaçamento entre o tempo de carreira e a idade de artistas que buscam seu reconhecimento pelo circuito de arte contemporânea no Brasil. Desse modo, jovem artista não cabe como categoria apenas para pessoas de alguma faixa etária socialmente considerada como jovem. Por exemplo, embora seja uma exceção, na pesquisa realizada, há artistas com três décadas de atuação, mas que participaram de editais voltados para tais jovens artistas. Isso porque, no que se refere à noção de legitimação - que, resumidamente, seria a autorização social recebida por um

o indivíduo a fim de atuar em determinadas searas (Sennett,

م 2001; Weber, 1999) -, tratando-se do campo da arte, um

ㄱ artista obtém sua legitimidade ou, como se poderia enca-

i rar, torna-se um profissional, quando seu nome e trabalhos

Ð passam a circular em exposições, residências artísticas,

prêmios, galerias, livros de arte, catálogos de exposições

ڤ entre outros. Ou seja, creio que, a partir do momento em

เ que a carreira artística de um indivíduo deixa de depen-

$\stackrel{1}{\wedge}$ der somente de suas inscrições e eventuais aprovações em

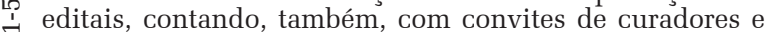

เo instituições, bem como com o diferenciado consumo de

ᄂ seus trabalhos (através do colecionismo, mas também em

2 publicações, por exemplo), tal artista angaria sua legiti-

ヘ̊ mação no campo. Não há propriamente um marco, como

¿ em outras áreas como a docência acadêmica que depende

i de concursos públicos que registram a legitimação de um

๓ै profissional. Em se tratando da arte, no entanto, o soma-

$>$ tório de ações e a circulação de nomes e trabalhos contri-

a buem para a compreensão de um artista como legitimado e

- não mais apenas um jovem artista ou artista emergente ou

$\stackrel{\pi}{\geq}$ ainda artista em início de carreira. Cabe mencionar tam-

స్ bém que, mesmo no campo da arte, há listas de artistas

que equacionam seu valor de mercado, sua circulação no

mundo da arte em instituições de grande porte e prestígio

U entre outros fatores, os quais contribuem para a compre-

ensão de tal processo de legitimação. Mas, nesses casos,

trata-se, por assim dizer, de um termômetro medido pelo

mercado de arte (sobre esse tema, ver: Marcondes, 2018;

ษ Quemin, 2013, 2015). nam o deslocamento de artistas de seus locais habituais de trabalho e (ou) residência por um período determinado, colocando-os em diálogo com novos atores sociais. Nesse sentido, elas são responsáveis por criar um novo fluxo de artistas no sistema de arte, em termos locais e globais, bem como em introduzir novas regras para a seleção e o reconhecimento de jovens artistas.

Dada a importância atual das residências artísticas, mostro, a seguir, quais são os procedimentos utilizados para a escolha de jovens artistas em três diferentes programas: o Programa Bolsa Pampulha, promovido, desde 2003, pela Prefeitura Municipal de Belo Horizonte, no Museu de Arte da Pampulha; a Residência Artística Red Bull Station, uma iniciativa financiada pela empresa austríaca Red Bull na cidade de São Paulo, desde 2013; e a Casa B-Residência Artística, lançada em 2016 pelo Museu do Bispo Rosário Arte Contemporânea (MBRAC), no Rio de Janeiro, com incentivo da Fundação Nacional de Arte (FUNARTE). Além disso, aponto algumas características do perfil dos artistas que vêm sendo selecionados pelos programas, como gênero e grau de escolaridade.

A pesquisa que fundamenta este artigo foi realizada entre 2014 e 2017. Incluiu dados de duas edições do Programa Bolsa Pampulha, realizadas entre os anos de 2013 e 2016. Da Casa B - Residência Artística foram obtidas informações de sua primeira edição em formato de edital aberto a inscrições, e da Residência Artística Red Bull Station foram coletados dados de cinco edições. ${ }^{4}$ Essa desigualdade no número de edições dos programas de residência artística ocorreu devido à diferente periodicidade de seus editais e à história singular de cada uma delas, como veremos adiante.

Conforme já mencionei, a problematização das residências artísticas e o entendimento de seu significado e efeitos no campo artístico

${ }^{4}$ A Residência Artística Red Bull Station contou com oito edições entre 2014 e 2017. Contudo, como o levantamento de seus dados foi realizado pelo site do programa, três edições ocorridas em 2014 ficaram de fora, pois, em relação a elas, não foi possível coletar alguns dados importantes para a realização deste trabalho. 
é recente, sendo a literatura sobre o assunto bastante escassa. Em 2009, Marcos José Santos de Moraes $^{5}$ defendeu a tese Residências artísticas: ambientes de formação, criação e difusão, na Faculdade de Arquitetura e Urbanismo da Universidade de São Paulo. Nela, Moraes mostra a proliferação das residências artísticas nas últimas décadas do século XX, e o aparecimento de grandes redes internacionais de difusão das residências, uma tendência relevante no atual universo da arte. O autor destaca o papel da rede holandesa Res Artis, da norte-americana Alliance of Artists Communities (AAC) e da taiwanesa Intra Asia Network, que permitem acesso à informação acerca de programas de residência artística pelo mundo, buscando apoiar diretamente artistas contemporâneos (Moraes, 2009, p. 20). Porém, mais do que isso, ele indica como as residências, na sua acepção, complementam o ensino formal em artes e, de certa forma, vêm propalar a possibilidade do afazer artístico ser uma atividade coletiva, substituindo a velha imagem do senso comum acerca dos ateliês dos artistas, onde trabalhavam isolados e sozinhos. ${ }^{6}$

Em 2014, a FUNARTE publicou o livro Mapeamento das Residências Artísticas no Brasil, organizado por Ana Vasconcelos e André Bezerra, com um conjunto de dados sobre as residências no país. No capítulo de sua autoria, Ana Vasconcelos afirma que:

[...] é importante frisar que um programa de residências artísticas consiste num conjunto de ações voltadas para o incentivo à experimentação, inovação, pesquisa e criação no campo das artes. Isto se dá, em geral, através do apoio financeiro ou não, concedido a artistas que, na maior parte das vezes, saem de seu lugar de origem para realizar residências em outras localidades. A instituição pode realizar o programa de residências artísticas por meio de

${ }^{5}$ Coordenador do curso de Artes Visuais da Fundação Armando Álvares Penteado (FAAP) e da residência artística promovida pela mesma instituição.

${ }^{6}$ A tese de doutoramento de Pucu (2017) também destaca esse aspecto coletivo do fazer artístico promovido pelas residências artísticas. A autora trata de alguns processos de residência artística, como a Remixofagia, realizada por três meses em 2014 no Centro Municipal de Arte Hélio Oiticica, do qual foi diretora. recursos oriundos de outros editais públicos e privados, por meio de seus próprios editais/recursos, ou qualquer outra forma de financiamento direto ou indireto. Os programas podem ainda conceder ou não apoio financeiro ao artista, sendo a instituição a responsável por arcar com parte dos custos ou com a totalidade deles. Os locais de realização das residências variam conforme o programa, podendo abranger desde um município até os mais diferentes países. Os programas podem ter como foco uma ou mais linguagens artísticas (circo, dança, teatro, artes visuais, música, arte digital, literatura, cinema). No que se refere à periodicidade, podem ser realizados em períodos pré-estabelecidos, anualmente, semestralmente, etc. Este quadro nos aponta para uma multiplicidade de perfis de programas de residência artística (Vasconcelos, 2014, p. 19).

As residências artísticas propiciam, portanto, em primeiro lugar, o deslocamento dos artistas que, ao deixarem o seu local habitual de criação, têm acesso a outros grupos e indivíduos, locais e ambientes que lhes permitem a vivência de novas experiências e trocas relevantes para o desenvolvimento de seu trabalho artístico. Deslocamento é, sem dúvida, a palavra-chave que se associa ao conceito corrente de residência artística. Em segundo lugar, o deslocamento dos artistas possibilita a formação de redes de contatos com museus, galerias, mercado de arte e profissionais das artes visuais de outros contextos, ampliando a inserção e promovendo o reconhecimento de artistas no mundo da arte. Essa nova configuração dos espaços de formação, meios de circulação e criação artística teria acarretado a internacionalização da arte e seu mais recente caráter cosmopolita (Heinich, 2014, p. 382). ${ }^{7}$

Cabe, no entanto, demarcar que essa experiência de deslocamento e esse desejo de internacionalização do campo artístico não é uma efetiva novidade, embora, como farei notar, as residências artísticas atuais tenham suas particularidades, pois são historicamente precedidas pelos chamados Prêmios de Viagem.

\footnotetext{
${ }^{7}$ De acordo com Moraes, "as residências artísticas tornaram-se uma parte fundamental do sistema artístico contemporâneo e sua presença se torna visível a partir dos anos 1960, com uma acentuada presença e atuação a partir de finais de 1980" (2009, p. 126).
} 
Institucionalizados, no Brasil em 1845, por iniciativa de Felix Émile Taunay, diretor da então Academia Imperial de Belas Artes (atual Escola de Belas Artes da Universidade Federal do Rio de Janeiro), os Prêmios de Viagem permitiram que inúmeros artistas aprofundassem suas questões estéticas, no Brasil ou na Europa (Luz, 2005, 2006). A institucionalização dos Prêmios de Viagem permitiu, inclusive, que artistas de famílias de poucos recursos fizessem viagem e estudo com apoio dos recursos do prêmio (a exemplo de Cândido Portinari, que foi à França por ser vencedor do prêmio em 1928).

As atuais residências artísticas também promovem o deslocamento dos artistas do local onde vivem para outro lugar, seja longe, em outro país, ou perto, no mesmo estado ou cidade, com a intenção de lhes dar apoio em sua experiência artística em contextos diferentes dos habituais. Todavia, se, anteriormente, apenas poucos indivíduos eram sagrados com os chamados Prêmios de Viagem, recebendo tal premiação por meio dos júris que compunham Exposições Gerais, mais tarde, Salão Nacional de Belas Artes, ${ }^{8}$ no momento atual, como será discutido a seguir, as residências são programas que independem de premiações, ou seja, artistas aplicam inscrições em editais próprios de residências e não necessariamente as recebem como o resultado de alguma premiação anterior. Sendo,

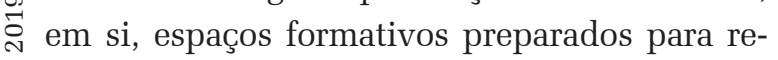
凶ં ceber artistas, então, por vezes, as residências

${ }^{8}$ A influência francesa, que aportou no Brasil com a Misన్̃ são Artística Francesa, trouxe as chamadas Exposições Gerais para o contexto do país, tendo a primeira ocorrido em

TH 1840. Mesmo após a queda da monarquia, em tempos da

U República, a exposição oficial não deixou de existir, mas

teve seu nome modificado para Salão Nacional de Belas

Artes. Passando por mudanças de nomes e regras, glórias e

dificuldades, essa exposição durou cerca de 150 anos, até encerrar-se na década de 1990. introdução de nova forma de criação que prescinde do ateliê individual; 3) incentivo à experimentação e à inovação; 4) formação de redes de artistas e agentes que integram o campo das artes. Neste artigo, entretanto, considero que as residências artísticas se tornaram uma etapa indispensável para a realização das aspirações de jovens artistas que buscam o reconhecimento e a legitimação de sua atuação no mundo da arte. Os editais voltados para as residências artísticas usam as categorias de jovens artistas, artistas em início de carreira e artistas emergentes, as quais, neste trabalho, foram agrupadas em uma só jovens artistas -, uma vez que estão vinculadas à idade e ao tempo de carreira dos candidatos aos programas, como explicito mais adiante.

\section{TRÊS DIFERENTES PROGRAMAS DE RESIDÊNCIA ARTÍSTICA NO BRASIL}

A origem e a história dos programas de residência artística são bastante variadas, embora guardem semelhanças no tocante aos objetivos de fomentar a produção dos artistas através de seu deslocamento e da possibilidade de troca com novo ambiente e entorno. Em 2003, o antigo Salão Nacional de Arte de Belo Horizonte foi transformado no Programa Bolsa Pampulha, uma residência artística destinada a jovens artistas de todo o país. O Salão Municipal de Belas Artes de Belo Horizonte (SMBA-BH) ou Salão de Arte da Capital fora criado em 1937, adquirindo diferentes nomes durante o século XX, como Salão Nacional de Arte Contemporânea e Salão Nacional de Arte da Prefeitura de Belo Horizonte em 1971. Em 1937, o Salão tinha o objetivo de atender às reivindicações de artistas mineiros por espaços e oportunidades de exibição de seus trabalhos. Em 1957, depois de 20 anos de atividades, o Salão foi transferido para o Museu da Pampulha ${ }^{9}$ e, em 1969, o ciclo dos Salões

${ }^{9} \mathrm{O}$ prédio ocupado pelo Museu foi o primeiro projetado por Oscar Niemeyer para o Conjunto Arquitetônico da 
Municipais deu lugar aos Salões Nacionais de Arte Contemporânea.

O Programa Bolsa Pampulha, criado por Adriano Pedrosa, à época curador do Museu de Arte Moderna da Pampulha, em Belo Horizonte,${ }^{10}$ tinha por objetivo a atualização do modelo de salão de arte. Segundo Pedrosa,

O formato de Salão nos pareceu antiquado e decidimos, com o apoio entusiasmado da Secretaria de Cultura e da direção do Museu, enfrentar o desafio de reformulá-lo. Muito se falou do anacronismo do modelo dos Salões de Arte, tão disseminados no Brasil, porém nenhum fora efetivamente revisado nesse sentido, com uma proposta de modelo alternativo (Pedrosa, apud Museu de Arte da Pampulha, 2017). ${ }^{11}$

O Bolsa Pampulha é, portanto, uma iniciativa de renovação de um antigo modelo expositivo. Apesar da mudança de formato para um programa de residência artística, em seus materiais de divulgação, ele é chamado de Programa Bolsa Pampulha e também de Salão de Arte de Belo Horizonte. Assim, a $6^{\mathrm{a}}$ edição do Programa Bolsa Pampulha também recebeu o nome de $32^{\circ}$ Salão de Arte de Belo Horizonte. Moura (2015), assistente de curadoria do $\mathrm{Mu}$ seu de Arte da Pampulha, na primeira edição do programa, afirma que:

Os próprios parâmetros que informavam o Salão, preterindo uns artistas a outros, exibindo-os sem pesquisa curatorial que não aquela chamada aberta e do júri de seleção, gerando exposições coletivas orientadas por critérios anacrônicos, muitas vezes limitados por gêneros artísticos, não atendiam de forma alguma a um museu que se reformulava e que se queria alinhado com as questões contempo-

Pampulha em Belo Horizonte. Originalmente projetado para ser um cassino, em 1957 passou a abrigar o Museu de Arte da Pampulha.

${ }^{10}$ Desde 2014, Adriano Pedrosa ocupa o cargo de diretor artístico do Museu de arte de São Paulo Assis Chateaubriand (MASP).

${ }^{11}$ Este excerto consta do folder de divulgação da mostra 60 Anos, Museu + Residência (2017-2018), realizada no/pelo Museu de Arte da Pampulha em virtude da finalização da $6^{\text {a }}$ edição do Programa Bolsa Pampulha. A frase atribuída a Adriano Pedrosa, de acordo com o material impresso, consta do texto do curador para o catálogo da primeira edição do Bolsa Pampulha, em 2003. Aproveito a oportunidade para agradecer ao Museu de Arte da Pampulha pelo envio dos catálogos das edições do Programa Bolsa Pampulha aqui analisadas, bem como do folder em questão e demais materiais que auxiliaram este trabalho. râneas. Assim, após uma série de consultas legais, o Salão Nacional de Arte de Belo Horizonte (denominação em uso) passou a ter acrescido seu nome com Bolsa Pampulha. Formulação a partir de uma lógica de fomento da produção, e não de reconhecimento a posteriori, a Bolsa Pampulha (depois mais comumente tratado como "o" projeto Bolsa Pampulha) foi uma espécie de pedra de toque para o programa do Museu. Tratava-se de uma maneira de aproximar o museu da produção emergente, mais arriscada, fazendo com que o Museu [...] apoiasse a dinamização do circuito local (Bolsa..., 2015, p. 18).

O processo de acompanhamento dos artistas e demais ações desenvolvidas no âmbito do Bolsa Pampulha distinguem, efetivamente, o programa do modelo dos salões de arte. No caso das residências, o deslocamento do artista para um local visando à sua imersão em contexto diferente de seu ambiente habitual de trabalho significa, com base na noção de site specific, ${ }^{12}$ que os trabalhos produzidos se vinculem, de alguma forma, à experiência que a residência oferece. As obras exibidas nos salóes de arte, no entanto, não respondiam a essa necessidade ou especificidade.

No Programa Bolsa Pampulha, os candidatos são selecionados por uma comissão composta por curadores, críticos e artistas mais experientes, que avalia portfólio, currículo, proposta de trabalho e carta de intenção enviados pelo candidato. Aos artistas escolhidos são oferecidas bolsas para cobrir os gastos com a estadia na cidade de Belo Horizonte no período estipulado pelo edital. ${ }^{13}$ Além de um ateliê de uso coletivo no Museu de Arte da Pampulha, os artistas selecionados participam de uma exposição coletiva, tendo sua produção registrada em um catálogo bilíngue (português e inglês).

${ }^{12}$ Esse conceito remete às experimentações artísticas iniciadas nas décadas de 1960 e 1970, quando o ambiente (seja esse o da galeria, da rua ou de um recanto natural) passou a ser incorporado à produção das obras de arte. As obras são construídas considerando o ambiente como parte da obra. Exemplar dessa linguagem artística é a obra Spiral Jetty, realizada por Robert Smithson em 1970, com pedras, areia e sal, no Great Salt Lake nos Estados Unidos.

${ }^{13}$ Se, na quarta edição do Bolsa Pampulha, realizada entre 2010 e 2011, os artistas recebiam bolsas para residir em Belo Horizonte por 11 meses consecutivos, na quinta edição, que abrangeu os anos de 2013 e 2014, o período de estadia foi reduzido para 5 meses. 
No edital de 2010, o Programa mineiro definiu o perfil do candidato, estabelecendo que ele deveria atender a um dos seguintes requisitos: 1) ter a idade de 35 anos como limite para inscrição no certame; 2) ou ter cinco anos de carreira contados a partir da primeira exposição individual; ou ainda 3) ter realizado duas exposições individuais. O único critério redefinido foi o número de exposições individuais, que aumentou para três. Dos programas pesquisados, o Bolsa Pampulha é o único a estabelecer critérios para definir os artistas com "produção emergente" a serem selecionados para a concessão de bolsa de residência artística. Nota-se que os critérios se baseiam na idade e (ou) carreira do candidato, definida pelas exposições individuais.

Diferentemente de outros programas, desde o início, o júri de seleção fica responsável pelo acompanhamento dos trabalhos desenvolvidos pelos jovens artistas em encontros presenciais. ${ }^{14}$ Mas essa tomada de posição pelo Bolsa Pampulha foi objeto de polêmica. Os posicionamentos adversos ao Programa remontam à sua criação, como mostra texto de Lagnado (2006), que respondeu diretamente aos críticos da iniciativa, que preferiam apostar no autodidatismo dos artistas, contrários que eram ao projeto de pesquisa e orientação:

\footnotetext{
o) O edital (da Bolsa Pampulha) traz pelo menos três questões de alta voltagem para o debate contemporâneo: da parte do crítico, em que consiste o processo de orientação?;da parte do artista, em que consiste fixar residência por um ano em Belo Horizonte?; da parte do momento da arte, o que os artistas contemporâneos procuram evidenciar? Não há como iniciar essa análise sem antes registrar que esse formato de substituição de Salão tem um saldo positivo inédito (Lagnado, 2006, p. 312).

Alguns anos depois, nota-se na introdução ao catálogo da $4^{a}$ edição do programa de residência, ocorrido entre 2010 e 2011, que Cohen

${ }^{14}$ Averiguou-se que, na $5^{\text {a }}$ edição do Programa Bolsa Pampulha, houve cinco encontros entre os artistas-residentes e o júri; além disso, o catálogo dessa edição informa que ocorreram três encontros entre os artistas-residentes e artistas locais.
}

defende a iniciativa, descrevendo sua experiência no acompanhamento do trabalho dos artistas participantes naquela edição do programa. Cohen afirma que seu trabalho foi de uma "curadora-orientadora” (Cohen, 2011, p. 15):

Quando não há, como é o caso do Brasil, um reconhecimento em níveis micro e macropolíticos, do valor da pesquisa, da prática e da produção artística, os jovens que investem energia, tempo e dinheiro em uma formação, e na própria produção de sua obra, não esperam que aquele investimento um dia vá gerar estabilidade financeira. Para ser artista, há que ter outro emprego que pague as dívidas mensalmente: fotógrafo, designer gráfico, tradutor, professor. Mas talvez trabalhar dobrado não seja o principal problema. O problema é justamente não contar com a valorização simbólica e financeira da arte como parte constituinte do contexto social em que estamos inseridos. Esse fator é o que leva o artista continuamente a se perguntar: mas, afinal, por que estou fazendo arte, e para quem?

Por essa e por outras razóes, iniciativas como a do Bolsa Pampulha são absolutamente necessárias para a formação dos profissionais que dependem de tempo de pesquisa para gerar obras que não necessariamente têm o ritmo industrial. A possibilidade de uma bolsa mensal para artistas por um ano, desvinculada do orçamento de produção ou exibição de obras, e voltada para a discussão de projetos, de ideias, pesquisa que pode vir a gerar uma prática consistente a longo prazo, não apenas serve como experiência para os dez artistas selecionados; contribui principalmente para a criação de um arcabouço que afirma a produção artística como patrimônio cultural (Cohen, 2011, p. 22-23).

Com 15 anos de atividades o Programa Bolsa Pampulha se distingue dos Programas que apresento a seguir. A Casa B - Residência Artística: Conexão, Imersão, Ocupação, promovida pelo Museu Bispo do Rosário Arte Contemporânea, por exemplo, abriu seu primeiro edital com apoio da $12^{\mathrm{a}}$ edição do Programa Rede Nacional FUNARTE Artes Visuais, ${ }^{15}$ no Rio de Janeiro, onde fica localizado. O Museu

${ }^{15} \mathrm{O}$ objeto do Programa Rede Nacional Funarte Artes Visuais, em sua $12^{\mathrm{a}}$ edição, foi o de fomentar projetos que promovessem o intercâmbio entre os estados federativos brasileiros por meio de oficinas, seminários e residências ligados às artes visuais. Disponível em: < http://www.funarte.gov. br/wp-content/uploads/2015/07/Edital-Rede-Nacional-Funarte-Artes-Visuais-12\%C2\%AA-Edi\%C3\%A7\%C3\%A3o. pdf $>$. Acesso em 24 de fevereiro de 2018 . 
promovia um programa de residência para artistas convidados pela instituição, e somente contou com financiamento externo para fazer uma chamada aberta em 2016.

O Museu Bispo do Rosário Arte Contemporânea está situado na Colônia Juliano Moreira, antigo manicômio do Rio de Janeiro. A Colônia ocupava $7.350 .000 \mathrm{~m}^{2}$ de terras que pertenciam ao antigo engenho de Nossa Senhora dos Remédios, desapropriadas em 1912 para dar lugar à Colônia de Psicopatas Homens de Jacarepaguá, inaugurada em 1924. A instituição teve seu nome alterado em 1935, para homenagear seu idealizador, o médico baiano Juliano Moreira. O lugar abrigou pessoas de toda sorte, desde mulheres divorciadas, sifilíticos, alcoólatras e pessoas em sofrimento psíquico. Foram internos do antigo manicômio a poetisa Stela do Patrocínio, o compositor Ernesto Nazareth e Arthur Bispo do Rosário, que dá nome ao Museu que salvaguarda mais de oitocentas obras de sua autoria. ${ }^{16}$

O Museu realiza exposições que colocam a obra de Bispo do Rosário em diálogo com os trabalhos de outros artistas contemporâneos. Além disso, tem um espaço anexo chamado Polo Experimental de Convivência, Educação e Cultura, onde funcionam oficinas voltadas aos usuários do serviço de saúde mental e à comunidade local, integrando os usuários e não usuários da saúde mental. Com o processo de Reforma Psiquiátrica, ${ }^{17}$ os manicômios vêm perdendo leitos para períodos longos de internação, e, assim, o território que antes abrigava

${ }^{16}$ Flavia Corpas tem se dedicado ao estudo da obra e da trajetória de Arthur Bispo do Rosário, sendo sua tese de doutoramento, Arthur Bispo do Rosario: do claustro infinito à instalação de um nome (2014), referência sobre o tema.

17 Em 1978, foi criado o Movimento de Trabalhadores em Saúde Mental (MTSM), um grupo de profissionais de saúde que questionava a qualidade do cuidado prestado dentro dos manicômios e buscava alternativas para superação da assistência centrada no modelo hospitalar de internação. Essa mobilização contribuiu para o desencadeamento da Reforma Psiquiátrica Brasileira. O movimento tem logrado êxito e, ao longo dos anos, tem conseguido a reducão progressiva dos leitos psiquiátricos existentes no Brasil. Na Colônia Juliano Moreira, ainda há internação em caráter de longa duração, mas, nesse caso, os profissionais têm buscado formas de reintegrar os usuários à sociedade. Contudo, os casos são específicos e, por exemplo, nem todos os usuários possuem famílias que podem recebe-los de volta. apenas o manicômio, hoje se constitui em um sub-bairro da região de Jacarepaguá, na zona oeste do Rio de Janeiro. O Polo Experimental de Convivência conta, ainda, com o Ateliê Gaia, integrado por um grupo de artistas, ex-internos da Colônia, além de outros serviços para usuários do serviço de saúde mental e da comunidade local.

A começar pelo local da residência, o Programa Bolsa Pampulha e a Casa B se distinguem. Enquanto o programa mineiro utiliza prédio da tradição modernista brasileira, a Casa $B$, em Jacarepaguá, traz vestígios da antiga Colônia Juliano Moreira, que marcam a especificidade do Polo Experimental onde funciona a residência. Outra diferença diz respeito ao período da residência. Na sexta edição do Bolsa Pampulha, os artistas receberam subsídios para morar em Belo Horizonte por seis meses, mas, na Casa B, o tempo de estadia foi de um mês.

Em sua primeira edição em 2016, a convocatória da residência Casa B ofereceu vaga para cinco artistas, sendo um de cada região do país, selecionados por um júri composto pelo curador do Museu e mais duas curadoras externas à instituição. O júri analisou as cartas de apresentação e os projetos estéticos a serem desenvolvidos na residência, além das propostas de workshop a serem oferecidas à comunidade, currículos e portfólios dos candidatos. Os selecionados foram contemplados com um prêmio em dinheiro (no valor de R\$ 6.000,00), para realizar residência por 30 dias na instituição. Além do valor em dinheiro, os artistas puderam utilizar um ateliê coletivo para a realização de suas obras. Os artistas selecionados tinham a obrigatoriedade de oferecer cursos para a comunidade local e contribuir com imagens e textos para uma publicação sobre o processo de residência. ${ }^{18}$ Destaque-se que a obrigatoriedade

${ }^{18}$ Os dados dos artistas participantes da Casa B foram obtidos através das fichas de inscrição dos artistas, enviadas ao Museu e avaliadas pelo júri de selecão. Cabe dizer também que a residência do Museu Bispo do Rosário Arte Contemporânea não era específica para jovens artistas, contudo, a partir dos dados dos artistas, apresentados adiante, será possível perceber que seus participantes podem ser enquadrados nesse perfil que vem sendo delineado através dos diferentes editais aqui analisados. 
de interação e troca com a comunidade local encontra-se apenas no edital da Casa B.

As diferenças entre os programas podem ser evidenciadas, uma vez mais, quando os comparamos com o programa da Residência Artística Red Bull Station. A sede do Red Bull Station, inaugurada em 2013, fica na cidade de São Paulo, em um prédio que antes abrigou uma estação de abastecimento elétrico, desativada em 2004. A iniciativa da empresa de bebidas que dá nome ao projeto ${ }^{19}$ teve seu início no Brasil através do projeto Red Bull House of Art, em São Paulo, entre os anos de 2009 e 2011, em dois prédios da capital paulistana, sendo um desdobramento do projeto anterior. Por ocasião da inauguração da nova sede, foi realizada a exposição Red Bull House of Art, com trabalhos dos artistas que realizaram a residência artística entre 2009 e $2011 .^{20}$ Red Bull House of Art é também o nome do projeto da empresa de bebidas que se desenvolve em Detroit, nos Estados Unidos.

Esse programa se define como "[...] uma plataforma de incentivo e fomento à arte contemporânea nacional emergente através da convergência de ações e pensamentos que ampliem a formação, a reЏexão, a produção e a crítica de maneira interdisciplinar". ${ }^{21}$ Seu foco é a arte contemporânea emergente no ๑ país, expressão que costumeiramente inclui Бे a produção de jovens artistas ou artistas em ¿্ं início de carreira. A cada edição, o programa

^ ${ }^{19}$ A Red Bull é uma empresa austríaca de bebidas energé-

$\infty$ ticas que vende em mais de 160 países. Tem uma receita

¿ de 3,2bilhões de euros (2015) e é conhecida por financiar

i eventos e equipes esportivas. Disponível em: <https://

๓. www.istoedinheiro.com.br/noticias/negocios/20101119/

$>$ homem-que-deu-asas-para-red-bull/31210>. Acesso em: 4 de fevereiro de 2018

${ }^{20}$ Mais sobre esse histórico pode ser consultado na página do Red Bull Station. Disponível em: < https://www.redbull. com/br-pt/conhe\%C3\%A7a-o-red-bull-station $>$. Acesso

${ }^{21}$ Edital da $12^{\mathrm{a}}$ edição do Red Bull Station - Residência Artística (2016). Disponível em: <http://www.redbullstation. com.br/inscricoes-para-12a-residencia-artistica-comecam-dia-22/> . Acesso em: 15 de março de 2017. contam com um ateliê no prédio do Red Bull Station em São Paulo e o acompanhamento de um curador. Como em outras iniciativas, a seleção é feita através da avaliação de fichas de inscrição, portfólios e currículos, por um júri de integrado pelo curador da residência e mais dois profissionais convidados (curadores, críticos, artistas ex-residentes no programa, entre outros). Nas primeiras edições, a seleção dos candidatos da Residência Artística Red Bull Station incluía uma entrevista, presencial ou por videoconferência, entre os candidatos e os membros do júri. ${ }^{22}$ Todavia o edital para a seleção dos artistas das $13^{\mathrm{a}}$ e $14^{\mathrm{a}}$ edições do programa, em 2017, não incluía a entrevista. ${ }^{23}$ Essa forma de seleção fora defendida por Lisette Lagnado para o Bolsa Pampulha, embora não tenha sido implementada.

\begin{abstract}
Analisar o dossiê de um candidato exige que se leve em consideração uma série de informações incompletas ou precárias, pelo simples fato de que se trata de um trabalho em puro devir. Na minha opinião, esse trabalho poderia ser completado mediante uma entrevista individual, que pode esclarecer dúvidas de ordem subjetiva (Lagnado, 2006, p. 313).
\end{abstract}

Os artistas selecionados para a residência artística do Red Bull Station devem residir na cidade de São Paulo, mas o programa não cobre os gastos de moradia, alimentação e transporte. A duração da residência passou por reformulações que reduziram visivelmente seu período: na $10^{\mathrm{a}}$ e na $11^{\mathrm{a}}$ edição, o período de residência era de 16 semanas (quatro meses); na $12^{\mathrm{a}}$ edição, foi reduzido para 8 semanas (dois meses); e na $13^{\mathrm{a}}$ e na $14^{\mathrm{a}}$ edição, o período previsto em edital foi reduzido para

\footnotetext{
${ }^{22}$ Os editais da $11^{\mathrm{a}}$ e da $12^{\mathrm{a}}$ edição da Residência Artística Red Bull Station contam com a etapa de entrevista e podem ser acessados pelos links seguir. Disponível em: <http://www.redbullstation.com.br/inscricoes/uploads/ edital/edital_12_pt.pdf $>$ e < $<$ http://www.redbullstation. com.br/inscricoes/uploads/edital/edital_11_pt.pdf $>$. Acesso em: 09 de março de 2018.

${ }^{23} \mathrm{O}$ edital que previu a realização das $13^{\mathrm{a}}$ e $14^{\mathrm{a}}$ edições da Residência Artística Red Bull Station pode ser acessado pelo link a seguir. Disponível

em: <http://www.redbullstation.com.br/inscricoes/uploads/edital/edital_13_14_pt.pdf $>$. Acesso em: 09 de março de 2018.
} 
4 semanas (um mês). ${ }^{24}$ Até a $12^{\mathrm{a}}$ edição, fazia parte das atribuições dos artistas residentes apresentar palestra sobre seus processos criativos, organizar uma oficina aberta ao público, doar uma obra de sua autoria, concebida no decurso da residência, ao acervo do Red Bull Station, apresentar trabalhos inéditos na exposição que culmina a residência, além de se comprometer com a conservação do espaço e em participar das programações da instituição. Entretanto, nas $13^{\mathrm{a}}$ e $14^{\mathrm{a}}$ edições, a palestra sobre o processo criativo do residente deixou de ser obrigatória, assim como se tornou facultativa a doação de obra para o acervo da entidade. Além do ateliê individual para trabalho, ela oferece aos artistas a exibição de suas obras em exposição coletiva, divulgação nas mídias utilizadas pelo espaço e um auxílio financeiro (no valor de $\mathrm{R} \$ 3.500,00$, na $13^{\mathrm{a}}$ e na $14^{\mathrm{a}}$ edição do programa, realizadas em 2017) para produção dos trabalhos a serem apresentados na exposição coletiva. ${ }^{25}$

Se, conforme venho assinalando, o deslocamento dos artistas de seus locais habituais de trabalho e sua interação com novo entorno é a questão central dos programas de residência artística, cujo objetivo é fomentar a produção através da vivência de uma experiência singular, pode-se imaginar, através dos exemplos dados acima, como elas diferem. O tempo de duração de cada uma das residências pode variar de um mês a dois anos, ${ }^{26}$ em lugares tão diferentes quanto um museu de tradição modernista, localizado em uma das áreas mais

${ }^{24}$ Acerca do tempo de duração das residências, consultar editais acima mencionados. Sobre o tempo de duração da $10^{\mathrm{a}}$ residência do programa, a informação não foi obtida através do edital que previu sua realização, mas por notícias que saíram na imprensa - disponível em: <https:// zupi.com.br/inscricoes-abertas-para-10a-residencia-artistica-red-bull-station/> . Acesso em: 09 de março de 2018.

${ }^{25}$ O Red Bull Station distribui catálogos sobre as residências, contudo isso se dá presencialmente, em sua sede em São Paulo. Buscou-se obter os catálogos junto à instituição através do serviço postal, como é feito em relação a outros eventos e processos de residência aqui analisados, porém não houve retorno da instituição.

${ }^{26}$ No caso da Bolsa Pampulha, vale lembrar que a duração do projeto é de dois anos, mas o tempo propriamente dito de residência dos artistas na cidade de Belo Horizonte, em sua $6^{\mathrm{a}}$ edição, foi de seis meses. turísticas da capital mineira, um museu na zona oeste do Rio de Janeiro, fora da zona turística da cidade, em área onde funcionou um manicômio e onde ainda há serviços de saúde mental, e um prédio histórico na capital de São Paulo, que é subsidiado por uma empresa internacional de bebidas. Apenas o Museu Bispo do Rosário de Arte Contemporânea oferece quartos aos artistas, os quais ficam próximos ao espaço de ateliê de uso coletivo; os outros projetos oferecem ateliês de uso coletivo e individual. Finalmente, o apoio financeiro aos artistas varia visivelmente: O Bolsa Pampulha concede uma bolsa para cobrir os gastos na cidade de Belo Horizonte, por seis meses; a Casa $B$ oferece um prêmio em dinheiro e moradia para os artistas; e o Red Bull Station apoia financeiramente a produção de obras dos artistas durante a residência. Além disso, note-se que há duas instituições públicas - um museu em Belo Horizonte e outro do Rio de Janeiro -, em geral com parcos recursos, mas que fomentam a formação e criação artísticas, e uma grande empresa multinacional que busca manter e divulgar sua imagem apoiando as artes e os esportes de toda sorte (inclusive a Fórmula 1).

É, portanto, a partir da diversidade institucional que cada residência oferece experiências únicas aos artistas, não apenas em relação ao contexto para o qual se deslocam e passam a trabalhar, mas em relação ao contato com outros artistas e profissionais das artes (curadores, críticos, entre outros) com, em geral, produções estéticas e experiências de vida diversas. ${ }^{27}$ Isso mostra, como argumento neste artigo, que o reconhecimento e a legitimação da carreira artística exigem uma experiência singular nas residências, fundamentando-se na diversidade de circuitos e linguagens artísticas

${ }^{27}$ Ao tratar da residência Cité Internationale des Arts, em Paris, que possui convênio, desde meados da década de 1990, com a Fundação Armando Alvares Penteado (FAAP), Moraes (2009) aponta a diversidade de linguagens estéticas a que são expostos os artistas residentes desse programa francês, indicando, ainda, seu caráter internacional, que a difere substancialmente das residências tratadas neste artigo. Em 2009, o programa francês contava com duzentos e oitenta e dois espaços individuais (apartamentos, ateliês), além de espaços coletivos, espaços expositivos, auditórios e sala de concerto (Moraes, 2009, p. 34). 
a partir de uma sociabilidade singular também fomentada por esses programas de residência.

\section{O PERFIL DOS JOVENS ARTISTAS RECRUTADOS}

Ao mesmo tempo em que se constata uma grande diversidade institucional e se evidencia que as experiências individuais dos artistas-residentes variam muito de acordo com o programa de residência escolhido (ou melhor, do programa de residência que os escolhe, seleciona e recruta), o perfil desses artistas não difere muito. Reunindo os dados sobre os artistas selecionados pelos três programas acima analisados, coletados entre 2014 e $2017,{ }^{28}$ foi possível obter dados sobre os 60 escolhidos, sendo observável que: 1) a maioria se encontra na faixa dos 25 aos 35 anos de idade; 2) são majoritariamente brasileiros, provenientes, sobretudo, da região Sudeste do país, especialmente das cidades de São Paulo e Rio de Janeiro; 3) possuem alto grau de escolaridade: a maioria é graduada (19 deles), um alto percentual estava cursando a pós-graduação (20 deles), além de haver três doutores e nove mestres; e 4) do total de 60 artistas, 27 foram identificadas como pertencentes ao gênero feminino e 33 ao mas$\sigma$ Culino. ${ }^{29}$ Esses dados demonstram o perfil de

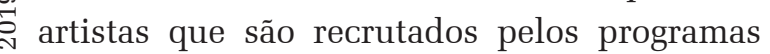
Фं de residência. Participando de tais programas, 这 angariam uma complementação em sua forथ

๙ ${ }^{28}$ Os dados aqui explicitados fazer parte da tese de doutoramento Arte e Consagração: Os Jovens Artistas da Arte rem em editais de residências artísticas bem como editais para exposições de arte encontra-se em minha já mencionada tese de doutorado (Marcondes, 2018, p. 166-178). rações de artistas; e 2) a definição da categoria de jovem. Com relação à crescente formação universitária dos artistas, Bueno (2016) afirma que a relação entre a arte contemporânea e o ensino universitário é fundamental para a expansão e manutenção do sistema artístico no Brasil. Para Bueno, entre a década de 1980 e o século XXI, "[...] presenciamos um fortalecimento das instituições de ensino das artes no país, ligadas à arte contemporânea, sendo a maior parte delas formada por entidades públicas e de nível universitário" (Bueno, 2016). O perfil dos artistas escolhidos pelos juris das residências artísticas aqui apresentado corrobora, portanto, o fato de que, cada vez mais, os jovens artistas encontram, no meio universitário, um espaço para sua formação e acolhida para seus trabalhos, os quais, muitas vezes, não são de interesse do mercado de comercialização de obras de arte, especialmente as performances, as instalações, entre outras práticas da arte contemporânea que enfatizam os processos artísticos em detrimento dos objetos artísticos.

Outra observação diz respeito à dificuldade em definir um jovem artista nos editais estudados. Sabe-se que a juventude é considerada sociologicamente uma fase da vida que implica o cumprimento de certas exigências e a aquisição de habilidades e competências determinadas pelo grupo e sua cultura para que um indivíduo entre na vida adulta. Para Bourdieu, entretanto as divisões etárias são arbitrárias uma vez que a juventude e a velhice não são dadas, mas construídas socialmente, na luta entre os jovens e os velhos (Bourdieu, 1983, p. 113). Em sua teoria sobre a distribuição do poder e sua distribuição social, Bourdieu afirma que pensar sobre fases da vida significa pensar sobre as lutas históricas e culturais que contribuem para a divisão do poder dentro de uma sociedade.

Desse modo, na realidade, a sociedade em seus diversos campos, através de indivíduos e instituições, encontra formas de recrutar e, consequentemente, legitimar alguns indivídu- 
os em detrimento de outros. Os selecionados recebem o aval social de seus pares para sua atuação profissional. No caso especifico aqui abordado, os artistas escolhidos obtêm não só a chance de aprimorar suas práticas profissionais, mas angariar visibilidade para suas poéticas artísticas, condição básica do trabalho artístico que é produzir bens e (ou) práticas estéticas e levá-los ao encontro do público.

Apesar de a experiência de deslocamento no campo da arte não ser uma novidade, afinal, como foi mencionado, existiram os chamados Prêmios de Viagem, no caso brasileiro, as residências artísticas podem ser encaradas algo novo e nascente no bojo da arte contemporânea, ${ }^{30}$ criando novas formas de concepção, produção e recepção de trabalhos de arte, de formação e circulação de artistas. Mas não menos importante: as residências criam novos modos de legitimação de artistas. Oferecem a experiência de deslocamento, circulação e formação artística, embora o façam para aqueles que são recrutados pelos júris de seleção, em geral compostos por artistas mais experientes, curadores, críticos de arte entre outros. Desse modo, os artistas e especialistas que assumiram posições dentro do campo artístico selecionam aqueles indivíduos que darão continuidade às práticas artísticas conforme as regras previamente estabelecidas por eles mesmos em interação com as instituições artísticas legitimadas e legitimadoras. É nesse sentido que as residências se tornaram não só relevantes para artistas iniciantes, que almejam seguir carreira como artistas profissionais, mas também para aqueles que têm posição consolidada. Pode-se dizer que o número crescente das residências, entre outras práticas, a exemplo dos editais voltados para exposições de arte, assegura a continuidade do campo artístico.

${ }^{30}$ No entanto, cabe fazer notar que deslocamentos geográficos e institucionais não são exclusivos do universo da arte contemporânea. Vale lembrar, por exemplo, que, no campo educacional, existem as bolsas sanduiche, que permitem a estudantes brasileiros se deslocarem para instituições ao redor do mundo a fim de aprimorarem sua formação.

\section{CONSIDERAÇÕES SOBRE AS RE- SIDÊNCIAS ARTÍSTICAS}

Se, em tempos da chamada arte clássica, era comum aos artistas produzirem quadros ou esculturas para coleções particulares de seus mecenas, ou mesmo afrescos para igrejas, no período da arte moderna, as exposições se tornaram o lugar por excelência de exibição das obras de arte, onde inúmeros delas são postas em diálogo entre si, dando lugar a um novo tipo de contemplação. A velocidade em que entram e saem as exposições em galerias atesta uma nova temporalidade contemplativa e demonstra a necessidade de o espectador ser estimulado pela quantidade de quadros diferentes que pode ver em curtos espaços de tempo (Simmel, 2016).

Em seu artigo Sobre Exposições de Arte, o sociólogo alemão Georg Simmel (1858-1918) as concebe como um fenômeno da modernidade que retrata a pluralidade e a pulsação de um mundo em que a profusão de informações passa a alterar os modos de ser e agir em sociedade e na sociedade. Isso porque as exposições de arte, nascentes no bojo da modernidade, reúnem, em um espaço limitado, uma série de trabalhos que podem ser do mesmo autor ou não, refletindo, na visão do autor alemão, um caráter distinto daquele dos museus com suas exposições permanentes.

Embora as exposições ainda vigorem em toda a sua força na atualidade, o surgimento das residências artísticas tornou mais complexos os processos de circulação e formação de artistas, de produção e recepção de trabalhos de arte. Afinal, se, nas exposições, ainda é regra que se exibam trabalhos "acabados", nas residências, o foco é o processo de realização dos trabalhos em contextos não usuais para seus autores, que podem ou não ser exibidos em exposições ao final do período de residência.

É possível tomar o período atual como sendo de abundância de editais de arte que 
viabilizam o trabalho de artistas, ${ }^{31}$ sendo especialmente importantes para jovens artistas, artistas emergentes, artistas em início de carreira. E, nesse contexto, enquanto alguns editais de arte, sobretudo os voltados para jovens artistas, promovem exposições coletivas dos selecionados, registrando, em catálogos, seus dados biográficos e imagens dos trabalhos dos participantes, outros fomentam o deslocamento dos artistas para espaços de interação social e trocas, como acabamos de ver.

A diferença entre os editais para exposições coletivas e para residências artísticas precisa ser acentuada aqui, embora a diversidade entre os editais seja tamanha, que, como já foi mencionado, um edital para residência artística pode, eventualmente, promover uma exposição dos trabalhos dos artistas que dela participam. De toda forma, não há como comparar as duas modalidades atualmente indispensáveis para que o jovem receba o aval para ingressar no mundo artístico. Todavia, é possível argumentar sobre sua função comum, já mencionada, que diz respeito à legitimação de artistas.

Ademais, é preciso destacar a distinção entre as atuais residências artísticas e os chamados Prêmios de Viagem. Afinal, neste caso, apenas alguns indivíduos recebiam tal honraria, o que lhes permitia uma experiência o de aprofundamento de seus saberes artísticos. Mas, no caso das residências, como foi visto, ๗ o número de selecionados, embora variável, 这 abarca mais indivíduos, e tais instituições

1ิ 31 Além das três residências artísticas tratadas neste artib. go, cabe mencionar outros editais que presentemente têm เ contribuído para a constituição e manutenção do campo

2 da arte brasileira, especialmente, no que diz respeito aos

๙ jovens artistas. Sem pretensão de citar todos os existentes,

¿ é interessante referenciar: o Abre Alas, promovido pela ga-

- leria A Gentil Carioca, do Rio de Janeiro; o Novíssimos, da

๗ Galeria IBEU, situada no Rio de Janeiro; o Salão Anapolino

$>$ de Arte, realizado pela Secretaria de Cultura da cidade de

- Anápolis; o Salão Paranaense, organizado pelo Museu de

- Arte Contemporânea do Paraná; o Salão de Abril, atual-

$\triangleq$ mente fomentado pela Secretaria de Cultura de Fortaleza,

స entre outros editais que contribuem para que artistas ex-

ponham seus trabalhos e tenham seus nomes inseridos no

circuito artístico, seja local e, em alguns casos, nacional,

U devido ao prestígio das mostras e mesmo a abertura a artis-

tas de diferentes regióes do país. Por fim, cabe mencionar

o site Mapa das Artes, que, frequentemente, reúne e divul-

ga editais do mundo da arte (ver: https://www.mapadasar-

$\circlearrowleft$ tes.com.br). lizadas nesse processo formativo. Assim, se, no caso dos Prêmios de Viagem, um artista recebia o prêmio como consagração por sua atuação nas exposições que legavam tal honraria, creio que as atuais residências artísticas constituem mais uma das partes do processo de legitimação artística. Ou melhor, no primeiro caso, artistas já saíam consagrados para suas viagens, tendo recebido um prêmio; já no caso das residências, tais artistas podem ainda estar fundamentando suas carreiras. Destarte, ao serem selecionados, se encaminham para um processo de formação, e não para recebimento de uma premiação (ao menos é isso que acredito ocorrer nos programas de residência aqui analisados).

Tomando-se os ensinamentos de Weber (1999) e Sennett (2001), é imprescindível demarcar que a legitimação de atores sociais lhes concede poder em termos sociais, possibilitando, portanto, que exerçam certos papéis sociais. No caso analisado, das residências artísticas, trata-se de uma nova configuração do universo da arte após o advento da arte contemporânea, a qual permite a visibilidade de artistas e complementa sua formação. Nesse sentido, as residências artísticas são parte de uma configuração social específica, composta por indivíduos e instituições interdependentes que, em interações, compõem o universo da arte. Uma vez parte da rede de instituições artísticas, pode-se tratar das residências artísticas como igualmente responsáveis pelo recrutamento de novos atores sociais a serem legitimados pelo universo da arte.

Em outra ocasião (Marcondes, 2018), analisando o processo de legitimação de jovens artistas no universo da arte contemporânea, foi possível constatar que faz parte das prerrogativas desse sistema de relações que seus profissionais e instituições estejam sempre em busca de novidades. Ou seja, curadores, críticos de arte, museus, galerias etc. estão constantemente buscando novos artistas e práticas estéticas a serem apoiadas, pois, como defini (Marcondes, 2018), há um desejo institucional 
pela novidade que contribui, desse modo, para a existência do universo da arte, que está em constante renovação - um processo que envolve desejo de renovação (novos artistas e novas práticas estéticas) e desejo de conservação (profissionais experientes e instituições selecionando e recrutando aqueles que serão legitimados). As residências artísticas fazem parte desse sistema das relações que conformam a arte contemporânea. Nesse sentido, atuam, justamente, selecionando e contribuindo para a formação de novos artistas que poderão vir a ser legitimados pelo universo da arte, sendo esse seu papel fundamental no atual universo da arte, além de reforçarem tendências presentes em outros campos da sociedade, como o desejo por deslocamento advindo de um mundo globalizado, que tensiona as relações entre localismo e globalidade.

Não é possível dizer se, futuramente, as residências permanecerão auxiliando os processos de legitimação e formação do universo da arte. Contudo pode-se argumentar que, presentemente, a elas é reservado um papel nevrálgico no fomento e no desenvolvimento do mundo da arte. São, portanto, importantes no processo de legitimação de artistas da arte contemporânea e no cumprimento das prerrogativas básicas das instituições e dos profissionais da arte.

Enviado para publicação em 30 de abril de 2019 Aceito em 31 de outubro de 2019

\section{REFERÊNCIAS}

BOLSA Pampulha 2010-2011. Belo Horizonte, 2011.

BOLSA Pampulha 2013-2014. Belo Horizonte, 2015.

BOLSA Pampulha 2015-2016. Belo Horizonte, 2017.

BOURDIEU, P. Questões de sociologia. Rio de Janeiro: Marco Zero Limitada, 1983.

BUENO, M. L. A Condição de artista contemporâneo no Brasil - entre a universidade e o mercado. In: QUEMIN, A.; VILLAS BÔAS, G. (Orgs.) Arte e vida social - pesquisas recentes no Brasil e na França. OpenEdition Press, 2016. Disponível em http://books.openedition.org/oep/482. Acesso em: 21. 04. 2017.

CASA B - Residência Artística. Museu Bispo do Rosário Arte Contemporânea. Rio de Janeiro, 2017.
COHEN, A. P. Introdução. In: Bolsa Pampulha 2010-2011. Belo Horizonte: Museu de Arte da Pampulha, 2011.

CORPAS, F. Arthur Bispo do Rosario: do claustro infinito à instalação de um nome. 2014. Tese (Doutorado) - PósGraduação em Psicologia Clínica do Departamento de Psicologia da PUC-RIO, Rio de Janeiro.

COSTA RIBEIRO, C. A. Desigualdades nas transições para a vida adulta no Brasil (1996 e 2008). Revista Sociologia \& Antropologia, Rio de Janeiro, v. 4, n. 2, p. 433-473, 2014.

EDITAL Bolsa Pampulha 2010-2011. Disponível e m http://www.cultura.gov.br/documents/10883/38605/editalbolsa-pampulha-2010.pdf/10a0e224-861e-45a0-8ad0959ff598a3f8. Acesso em: 20. 08. 2017.

ERBER, P. Breachingthe frame - the riseofcontemporaryart in Brazil and Japan. California: UniversityofCalifornia Press, 2015.

FÉRES, L.; MAFRA, M. Apresentação. In: Bolsa Pampulha 2013-2014. Belo Horizonte: Museu de Arte da Pampulha, 2014.

FUNDAÇÃO NACIONAL DE ARTES (Funarte). Edital da $12^{a}$ edição do Programa Rede Nacional Funarte Artes Visuais em sua $12^{a}$. Disponível em http://www.funarte.gov.br/wpcontent/uploads/2015/07/Edital-Rede-Nacional-FunarteArtes-Visuais-12\%C2\%AA-Edi\%C3\%A7\%C3\%A3o.pdf . Acesso em: 24. 02. 2018.

HEINICH, N. Práticas da arte contemporânea: uma abordagem pragmática a um novo paradigma artístico. Revista Sociologia \& Antropologia, Rio de Janeiro, v. 04 , n.02, p. 373-390, 2014.

ISTO É DINHEIRO. O Homem que deu Asas para a Red Bull. Disponível em https://www.istoedinheiro.com.br/ noticias/negocios/20101119/homem-que-deu-asas-parared-bull/31210. Acesso em: 24. 02. 2018.

LAGNADO, L. Bolsa Pampulha: O meio e a formação do artista hoje. In: FERREIRA, G. (Org.) Crítica de arte no Brasil: temáticas contemporâneas. Rio de Janeiro: Funarte, 2006.

LUZ, A. A. Uma breve história dos salões de arte - da Europa ao Brasil. Rio de Janeiro: Caligrama, 2005.

LUZ, A. A. Salões oficiais de arte no Brasil - um tema em questão. Arte \& Ensaios, Rio de Janeiro, n. 13, 2006.

MAPA das arte. 2019. Disponível em https://www. mapadasartes.com.br. Acesso em: 29. 10. 2019.

MARCONDES, Guilherme. Arte e Consagração: os jovens artistas da arte contemporânea. 2018. Tese (Doutorado) Programa de pós-graduação em sociologia e antropologia da Universidade Federal do Rio de Janeiro.

MORAES, M. J. S. de. Residências artísticas: ambientes de formação, criação e difusão. 2009. Tese (Doutorado) Faculdade de Arquitetura e Urbanismo da USP, São Paulo.

MOURA, R. Outras Lembranças da Pampulha. In: Bolsa Pampulha 2013-2014. Belo Horizonte: Museu de Arte da Pampulha, 2015.

PEDROSA, A. Excerto de seu texto para o catálogo Bolsa Pampulha 2003-2004. In: 60 Anos, Museu + Residência. Folder informativo de exposição. Belo Horizonte, 2017.

PUCU, I. Arte como trabalho (e vice-versa). 2017. Tese (Doutorado) - Programa de Pós-Graduação em Artes Visuais, Linha de pesquisa em História e Crítica de Arte da UFRJ, Rio de Janeiro.

QUEMIN, A. Les stars de l'artcontemporain - notoriété et consécration artistiquesdansles arts visuels. Paris: CNRS Éditions, 2013.

The impact of nationality on the contemporary art market. Revista Sociologia \& Antropologia, Rio de Janeiro, v. 05, n. 03, p. 825-855, 2015 
RED BULL STATION. Conheça o Red Bull Station. Disponível em https://www.redbull.com/br-pt/ conhe\%C3\%A7a-o-red-bull-station. Acesso em: 15. 03. 2017.

Edital da $11^{a}$ edição da residência artística Red Bull Station. 2015. Disponível em http://www.redbullstation. com.br/inscricoes/uploads/edital/edital_11_pt.pdf. Acesso em: 09. 03. 2018.

Edital da $12^{a}$ edição da residência artística Red Bull Station. 2016. Disponível em http://www.redbullstation. com.br/inscricoes-para-12a-residencia-artistica-comecamdia-22/. Acesso em: 15. 03. 2017.

Edital das $13^{a}$ e $14^{a}$ edicõos da residência artística Red Bull Station. 2017. Disponível em http:// www.redbullstation.com.br/inscricoes/uploads/edital/ edital 1314 pt.pdf. Acesso em: 09. 03. 2018.

Residências Artísticas. Disponível http://www.redbullstation.com.br/residencias/14a-edicao/. Acesso em: 15. 03. 2017.

SCOVINO, F. A Vontade poética no diálogo com os bichos: o ponto de chegada de uma arte participativa no Brasil. Arte \& Ensaios, Rio de Janeiro, v. 10, p. 27-35, 2003.
SENNETT, R. Autoridade. Rio de Janeiro: Record, 2001.

SIMMEL, G. Sobre exposições de arte. In: VILLAS BÔAS, G.; OELZE, B. (Orgs.) Georg Simmel - arte e vida: ensaio de estética sociológica. São Paulo: Hucitec, 2016. p 159-166.

VASCONCELOS, A. Apontamentos para a construção de um programa Funarte de residências artísticas. In: VASCONCELOS, A.; BEZERRA, A. (Orgs.) Mapeamento de Residências Artísticas no Brasil. Rio de Janeiro: FUNARTE, 2014.

VILLAS BÔAS, G. Como a Arte (Contemporânea) se Apresenta? Sobre a Atualidade de A Moldura de Georg Simmel. Revista Novos Rumos Sociológicos, Pelotas, v. 5, n. 7, jan./jul, 2017.

WEBER, M. Economia e sociedade. Brasília: UNB, 1999. v. 1.

ZUPI. Lançamento da $10^{a}$ Residência Artística Red Bull Station. Disponível em https://zupi.com.br/inscricoesabertas-para-10a-residencia-artistica-red-bull-station/. Acesso em: 09. 03. 2018. 


\section{DISPLACEMENT, TRAINING AND LEGITIMATION: an analysis of artistic residency programs in Brazil}

\author{
Guilherme Marcondes
}

In the universe of Brazilian contemporary art, public or private institutions annually publish notices aimed at young artists, whose purpose is to encourage their displacement to different spaces of social interaction and exchanges, in order to encourage their production. In the residences, the artist complements and improves his formation through new experiences with the surroundings, developing his work away from the usual environment. This article aims to understand how such programs have altered the processes of formation and legitimation of artists in Brazil. For this, the selection notices for three artistic residency programs are analyzed: the Programa Bolsa Pampulha, promoted since 2003 by the Belo Horizonte City Hall at the Museu de Arte da Pampulha; the Casa B-Residência Artística, launched in 2016 by the Museu do Bispo Rosário Arte Contemporânea (MBRAC), in Rio de Janeiro, with the encouragement of FUNARTE; and the Residência Artística Red Bull Station, an initiative funded by the Austrian company Red Bull in São Paulo, since 2013.

KEYwORDs: Contemporary art. Young artists. Artistic residences. Displacement. Legitimation. Career.

\section{DÉPLACEMENT, FORMATION ET LÉGITIMATION: une analyse des programmes de résidence artistique au Brésil}

\author{
Guilherme Marcondes
}

Dans l'univers de l'art contemporain brésilien, les institutions publiques ou privées publient annuellement des avis destinés aux jeunes artistes, dont le but est d'encourager leur déplacement vers différents espaces d'interaction et d'échanges sociaux, afin d'encourager leur production. Dans les résidences, l'artiste complète et améliore sa formation à travers de nouvelles expériences avec l'environnement, en développant son travail loin de l'environnement habituel. Cet article vise à comprendre comment ces programmes ont modifié les processus de formation et de légitimation des artistes au Brésil. À cette fin, les avis de sélection pour trois programmes de résidence artistique sont analysés: le Programa Bolsa Pampulha, promu depuis 2003 par la mairie de Belo Horizonte au Museu de Arte da Pampulha; la Casa B-Residência Artística, lancée en 2016 par le Museu do Bispo Rosário Arte Contemporânea (MBRAC), à Rio de Janeiro, avec l'encouragement de FUNARTE; et la Residência Artística Red Bull Station, une initiative financée par la société autrichienne Red Bull à São Paulo, depuis 2013.

Mots-CLÉs: art contemporain. Jeunes artistes. Résidences artistiques. Déplacement. Légitimation. Carrière.
Guilherme Marcondes - Pós-doutorando (bolsista PNPD/CAPES) no Programa de Pós-Graduação
em Sociologia da Universidade Estadual do Ceará. Doutor e mestre no Programa de Pós-Graduação
em Sociologia e Antropologia da UFRJ. Pesquisador associado ao Núcleo de Sociologia da Cultura
da Universidade Federal do Rio de Janeiro (NUSC/UFRJ) e do GRUA - Grupo de Reconhecimento de
Universos Artísticos/Audiovisuais: http://www.grua.art.br (CNPq). Trabalha com temas relacionados
à sociologia da arte, à arte contemporânea, à sociologia da cultura e as questões étnico raciais, com
especial interesse sobre os processos de legitimação. Publicações recentes: Com quantos sociólogos se
desenvolve um programa de pesquisa em Sociologia da Arte? Resenha sobre o livro Um Vermelho Não é
Um Vermelho. INTERSEÇÕES (UERJ), v. 21, p. 488-494, 2019; Aspectos da crítica sobre jovens artistas
nas páginas do Jornal do Brasil (1950-2000). Teoria e Cultura, v. 14, p. 87-102, 2019; Arte, Juventude
e Legitimação: uma análise comparativa sobre jovens artistas da arte contemporânea nos contextos
brasileiro e uruguaio. Revista Brasileira de Sociologia, v. 7, p. 105-134, 2019; Procuram-se (Jovens)
Artistas. In: Paula Guerra; Lígia Dabul. (Org.). De Vidas Artes. 1ed.Porto, Portugal: Universidade do Porto,
2019, pp. 129-150. 
